\title{
Treatment of digital ulcers with oxygen-ozone therapy in a patient with systemic sclerosis
}

\author{
Hilary Riva, ${ }^{1}$ Brenno Balestra, ${ }^{2}$ Olivier Giannini, ${ }^{2}$ Giuseppe Bonforte $^{1}$ \\ ${ }^{1}$ Dialysis Unit, Beata Vergine Hospital, Mendrisio; ${ }^{2}$ Department of Internal Medicine, Beata Vergine Hospital, \\ Mendrisio, Switzerland
}

\begin{abstract}
Patients with systemic sclerosis often suffer from Raynaud's phenomenon and in the most severe cases it causes digital ulceration and difficult healing. Treatment for these complications are not always resolutive and sometimes not well tolerated.

The $\mathrm{O}_{2} \mathrm{O}_{3}$ therapy is a gas mixture that has several demonstrated effects including antiseptic, painkiller, microcirculation vasodilator, oxygen metabolism regulator and immunomodulation, and it can be personalised, administered to individual patient requirements.

We decided to offer this treatment to our patients after the failure of traditional drugs and surgery without influencing the therapeutic program. The results obtained are interesting, and though more studies are needed to better understand the exact mechanism of action of $\mathrm{O}_{2} \mathrm{O}_{3}$ therapy, we believe that in the meantime, this therapy should be considered as treatment for the most severe cases.
\end{abstract}

Correspondence: Hilary Riva, Dialysis Unit, Beata Vergine Hospital, Via Alfonso Turconi 23, Mendrisio 6850, Switzerland.

E-mail: riva.hilary@gmail.com

Acknowledgements: the treatment of this patient has been possible only thanks to the experience and dedication in Oxygen-Ozone Therapy of Dr. Giuseppe Bonforte.

Key words: Systemic sclerosis; Complementary therapies; Oxygenozone therapy; Digital ulcers.

Conflict of interest: the authors declare no potential conflict of interest.

Note: written consent has been obtained from the patient.

Received for publication: 10 September 2017

Accepted for publication: 14 September 2017.

(C) Copyright H. Riva et al., 2017

Licensee PAGEPress, Italy

Ozone Therapy 2017; 2:7061

doi:10.4081/ozone.2017.7061

This article is distributed under the terms of the Creative Commons Attribution Noncommercial License (by-nc 4.0) which permits any noncommercial use, distribution, and reproduction in any medium, provided the original author(s) and source are credited.

\section{Introduction}

Systemic sclerosis is an uncommon connective tissue disease, which is characterized by increased fibrotic tissue growth and microcirculation abnormalities.

Almost all these patients suffer from Raynaud phenomenon that causes digital ulceration or skin infarction. The same process can involve other organs, e.g. the musculoskeletal, renal, pulmonary, cardiac, and gastrointestinal systems, with heterogeneous clinical manifestation by multisystem involvement.

The pathogenesis of the systemic sclerosis is a complex and not definitive hypothesis of vascular injury with endothelial cell and platelet activation, immune dysregulation with inflammatory cytokines ad fibroblast activation. ${ }^{1}$

To date, no therapy has been shown to significantly alter the natural progression of the disease.

Treatment for Systemic Sclerosis is complex, targeting the organs involved with results often being unsatisfactory. In skin lesions the only tools available before starting an immunosuppressive therapy are patient education and vasodilator drugs, if tolerated. ${ }^{2}$

Alternative medicine did not show clear results on microcirculation, Raynaud phenomenon, pain, ${ }^{3}$ and consequently on quality of life.

Oxygen-ozone therapy $\left(\mathrm{O}_{2} \mathrm{O}_{3}\right.$ therapy) is a complementary therapy. This therapy is based on the use of a gas blend of oxygen and ozone that can be administered subcutaneously as pure gas, intravenously mixed with patient blood (auto-haemo infusion), by direct skin contact creating a hyperbaric compartment with a bag or by rectal gas insufflation. ${ }^{4}$

The $\mathrm{O}_{2} \mathrm{O}_{3}$ mixture has several effects, in particular, antiseptic, painkiller, microcirculation vasodilator, oxygen metabolism regulator and immunomodulation. ${ }^{4-6}$ Some studies demonstrate that despite $\mathrm{O}_{2} \mathrm{O}_{3}$ is an oxidant gas, its use in therapeutic range concentrations improves the endogenous antioxidant regeneration, the growth factors (VEGF, TGf- $\beta$, INF- $\gamma, 6 \mathrm{FGF}$ ) and nuclear factors (caspase, NRF-2, HIF $\alpha$, NFKB) expression. 4,6,7

In literature there are several reports on successful uses in the treatment of diabetes mellitus ulcers ${ }^{8}$ and herniated lumbar disc, ${ }^{9}$ but its main limit is that no RCTs have been carried out.

\section{Case Report}

Here we present the case of a 67-year-old Caucasian woman referred to our service of $\mathrm{O}_{2} \mathrm{O}_{3}$ therapy.

She had history of limited cutaneous form for 10 years evolved into systemic sclerosis with associated secondary Sjögren's 
Syndrome, severe esophageal dysomotility, constipation, scleroderma limited to the hands, forearm and face, telangiectasia, elbow ulcers due to calcium deposits and infected ulcers of the digits.

Immunoassay panel: anti-nuclear antibodies $1 / 256$, anti-centromere positive, anti-Scl70 negative. Pathologic capillaroscopy with late scleroderma pattern. The diagnosis was made in 2007 and the first event was a severe digital ischemia. Afterwards that digital ulcers appeared on both hands and no resolutive therapy were found to heal and to reduce the risk of ulcer infections, and some of them were not tolerated, antibiotics, surgical debridement, intravenous prostaglandin, painkillers-anti-inflammatory drugs, calcium-antagonists, orthopedic supports.

The prescribed therapy included Bosentan $250 \mathrm{mg} /$ day, longacting release Octeotride for the severe gastrointestinal involvement, Losartan $50 \mathrm{mg}$, acetyl salicylic acid $100 \mathrm{mg}$, artificial eye drops.

On first examination she had edematous and cyanotic fingers and ulcers on the $2^{\text {nd }}$ and $3^{\text {rd }}$ finger of the right hand and on the $3^{\text {rd }}$ finger of the left hand. Treatment with the hyperbaric bag to both hands was started associated to subcutaneous $\mathrm{O}_{2} \mathrm{O}_{3}$ administration, twice a week. To enhance the effect of the therapy 6 auto-hemo infusions were made at the end of the previous treatments, then these were substituted with rectal gas insufflation to avoid peripheric vein puncture. No local discomfort was experienced.
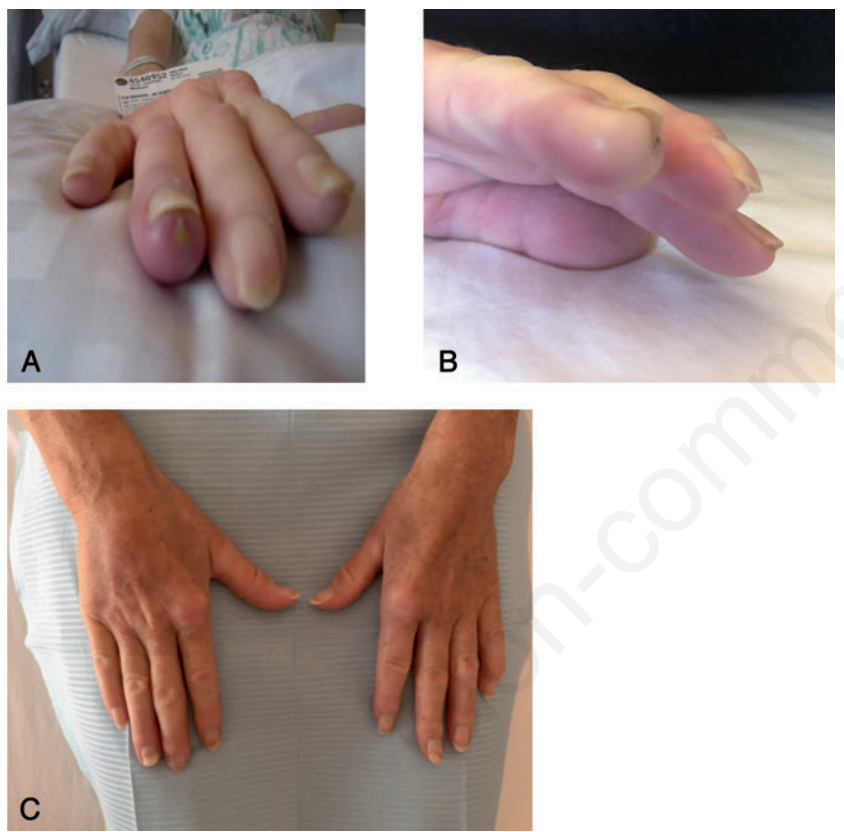

Figure 1. Patient's right hand before starting $\mathrm{O}_{2} \mathrm{O}_{3}$ therapy: acrocyanosis, digital ulcers and tissue edema ( $\mathrm{A}$ and $\mathrm{B})$; patient's hands after two months of treatment: complete lesions healing $(\mathrm{C})$.
The patient after two weeks of $\mathrm{O}_{2} \mathrm{O}_{3}$ therapy referred to an improvement in pain and edema, which resulted in better mobility. A month later the patient spontaneously decreased painkillers because ulcers had healed. The therapy was stopped for a month but symptom recrudescence was noticed, so a maintenance therapy was instituted twice a week. This therapy has now been continuing for over a year (Figure 1).

\section{Conclusions}

The $\mathrm{O}_{2} \mathrm{O}_{3}$ therapy demonstrated a safe profile and it has been a useful painkiller. No ulcer infection occurred during the treatment period and complete wound healing was obtained. The exact mechanism of action of this solution is not fully known, but its anti-inflammatory effects and its action on microcirculation play a central role. No case reports of this modality of treatment are present in literature, thus more experience is needed before giving definitive advice regarding frequency of maintenance treatment.

\section{References}

1. Gabrielli A, Avvedimento EV, Krieg T. Scleroderma. New Engl J Med 2009;360:1989.

2. Kowal-Bielecka O, Landewé R, Avouac J, et al. EULAR recommendations for the treatment of systemic sclerosis: a report from the EULAR Scleroderma Trials and Research group (EUSTAR). Ann Rheum Dis 2009;68:620-8.

3. Malenfant D, Catton M, Pope JE. The efficacy of complementary and alternative medicine in the treatment of Raynaud's phenomenon: a literature review and meta-analysis. Rheumatology 2009;48:791-5.

4. Bocci V, Borrelli E, Travagli V, Zanardi I. The ozone paradox: ozone is a strong oxidant as well as a medical drug. Med Res Rev 2009;29:646-82.

5. Sharma M, Hudson JB. Ozone gas is an effective and practical antibacterial agent. Am J Infect Control 2008;36:559-63.

6. Elvis M, Ekta JS. Ozone therapy: a clinical review. J Nat Sci Biol Med 2011;2:66-70.

7. Al-Dalain SM, Martínez G, Candelario-Jalil E, et al. Ozone treatment reduces markers of oxidative and endothelial damage in an experimental diabetes model in rats. Pharmacol Res 2001;44:391-6.

8. Liu J, Zhang P, Tian J, et al. Ozone therapy for treating foot ulcers in people with diabetes. Cochrane Database Syst Rev 2015;27:CD0084749.

9. Steppan J, Meaders T, Muto M, Murphy KJ. A metaanalysis of the effectiveness and safety of ozone treatments for herniated lumbar discs. J Vasc Interv Radiol 2010;21:534-48. 